\title{
Dying later, surviving longer
}

\author{
Dominic Wilkinson, ${ }^{1,2}$ James Weitz ${ }^{2}$
}

Most children who die in the UK have an underlying chronic illness, and the majority of these deaths take place in a paediatric intensive care unit (PICU). ${ }^{1}$ The overall community burden of paediatric chronic illness is increasing as the population expands and as children with chronic conditions live longer. Improvements in public health measures, and in the recognition and management of paediatric critical illness, mean that children with chronic conditions are increasingly the majority population in PICU.

Plunkett and Parslow describe a shift in the timing of death in PICUs in England and Wales over the last decade. ${ }^{2}$ They observed an increase in the average length of stay for children who died (about 3 days longer, on average, in 2013 than in 2003) and a corresponding increase in the proportion of children dying after more than 4 weeks of intensive care; in 2013, approximately $12 \%$ of deaths in PICU occurred late (after 28 days), compared with only about $8 \%$ a decade earlier.

What should we make of this finding? Does it represent a failure of end-of-life decision-making? Plunkett and Parslow point to this, suggesting that children with life-limiting illnesses are now dying after a long PICU admission rather than experiencing an early death in PICU. The authors conjecture that this may reflect changes in patient and public expectations of healthcare, increased shared decisionmaking and fear of litigation. ${ }^{2}$ It seems likely that some of this delay does relate to changes in the locus of decision-making in intensive care, with recognition of a zone of parental discretion in decisions. ${ }^{3}$ Decision-making regarding the end of a child's life is not a straightforward process, however. The time from first discussion of withdrawal of life-sustaining treatment to a decision to proceed is hugely variable. Clinician attitudes and beliefs, the number

\footnotetext{
${ }^{1}$ Faculty of Philosophy, Oxford Uehiro Centre for Practical Ethics, University of Oxford, Oxford, UK; ${ }^{2}$ Department of Paediatric Intensive Care, John Radcliffe Hospital, Oxford, UK

Correspondence to Dr Dominic Wilkinson, Oxford Uehiro Centre for Practical Ethics, Suite 8, Littlegate House, St Ebbes St, Oxford OX1 1PT, UK;

dominic.wilkinson@philosophy.ox.ac.uk
}

of professionals involved, as well as the relationship between clinician and parents contribute to delays in the limitation of treatment.

However, to put the findings in perspective, it is important to recognise that late deaths are not the norm. In PICU, $88 \%$ of deaths occurred within 28 days of admission. We should also note the other substantial changes in the epidemiology of PICU admission and mortality over the same period. While PICU admissions have risen by $15 \%$ from approximately 14000 per year in 2004 to 16000 per year in 2013, mortality rates have fallen. ${ }^{4}$ The fall in mortality is not simply a reflection of broader admission criteria with patients who are less sick being able to be accommodated in PICU. There were approximately 170 fewer deaths in PICUs in 2013, compared with a decade earlier, despite the substantial increase in workload. ${ }^{4}$

So, the news is not all bad. Indeed, even the authors' main finding could be seen as positive if expressed in another way. The corollary of finding that children are dying later in modern intensive care is that they are surviving longer. Parents, facing the death of their child, had an additional 3-4 days with their child, on average, in 2013 compared with 2003.

Should we then be worried that children are dying later in paediatric intensive care? One reason for concern is that children who die after a month or more of intensive treatment will have accumulated a substantial burden of treatment. In one study of Canadian PICUs, 50\% of children were reported to undergo 12 or more painful procedures per day, for example, endotracheal suction, venepuncture, vascular access and surgery. ${ }^{5}$ While the majority of such children were receiving pharmacological pain management, it is difficult to assess pain and pain-related distress in mechanically ventilated children, and it is likely that children experience at least intermittent pain and discomfort during their PICU stay. Clinicians may feel, perhaps justifiably, that death after a prolonged stay in intensive care is a particularly bad death for the child, and should be avoided wherever possible. In addition, increasing length of stay, particularly increases in very long stays in PICU, necessarily impact the total cost of intensive care and the availability of paediatric intensive care beds. From the latter point of view, the findings of Plunkett and Parslow are reassuring. They found that there was no increase in the total number of bed-days occupied by children who ultimately died; in fact, such children occupied a smaller proportion of intensive care unit beds-approximately $9 \%$ of bed-days in 2013, compared with about $11 \%$ in $2003 .^{2}$

If we could identify early in their stay (or even prior to admission), children who will not survive, there would be a strong ethical case for avoiding prolonged intensive care prior to death. But, of course, the practical challenge is in identifying those children. In many cases, there is inevitable uncertainty about both short-term and long-term survival. In the face of uncertainty, it is usually ethically appropriate to involve parents in decisions and to defer to their views about treatment. ${ }^{3}$ Such uncertainty does not necessarily disappear with the passage of time. A large longitudinal cohort study from Melbourne found that $60 \%$ of children who stayed in intensive care for more than 4 weeks survived to discharge from hospital, and more than 50\% of survivors had no or mild disability. ${ }^{6}$

Changes in the demographics of paediatric intensive care represent both an achievement and a challenge. There is reason to think that these demographic trends will continue, and that advances in paediatric intensive care will prevent death in childhood for some, while merely deferring or delaying death for others. The latter may be the inevitable price of the former. If that is the case, we need to work hard to diminish the burden of long intensive care stays. That means attention to symptom management, careful advance care planning and avoidance of non-beneficial treatments where it is possible to identify them. It also means being aware of, and working to mitigate, the emotional and psychological burden of prolonged intensive care on families and on staff.

Twitter Follow Dominic Wilkinson at @NeonatalEthics

Contributors DW wrote the first draft of this editorial. JW edited and contributed to the paper.

Funding DW was supported for this work by a grant from the Wellcome trust WT106587/Z/14/Z.

Competing interests None declared.

Provenance and peer review Commissioned; internally peer reviewed.

To cite Wilkinson D, Weitz J. Arch Dis Child 2016;101:783-784. 


\section{Editorial}

Received 27 April 2016

Revised 22 June 2016

Accepted 27 June 2016

Published Online First 18 July 2016

\section{Linked}

- http://dx.doi.org/10.1136/archdischild-2015-309592

Arch Dis Child 2016;101:783-784.

doi:10.1136/archdischild-2016-310637

\section{REFERENCES}

1 Ramnarayan P, Craig F, Petros A, et al. Characteristics of deaths occurring in hospitalised children: changing trends. J Med Ethics 2007;33:255-60.

2 Plunkett $P$, Parslow R. Is it taking longer to die in Paediatric Intensive Care in England and Wales. Arch Dis Child 2016;101:798-802.

3 Larcher V, Craig F, Bhogal K, et al. Making decisions to limit treatment in life-limiting and life-threatening conditions in children: a framework for practice. Arch Dis Child 2015;100(Suppl 2): s3-23.
4 Paediatric Intensive Care Audit Network. PICANET: a decade of data. Leeds, UK: Universities of Leeds and Leicester, 2014.

5 Stevens BJ, Abbott LK, Yamada J, et al. Epidemiology and management of painful procedures in children in Canadian hospitals. CMA 2011;183:E403-10.

6 Namachivayam P, Taylor A, Montague T, et al. Long-stay children in intensive care: long-term functional outcome and quality of life from a 20-yr institutional study. Pediatr Crit Care Med 2012;13:520-8. 